\title{
ANALISIS CITRA PERMUKAAN ISOLASI LISTRIK DARI BAHAN LDPE-NR AKIBAT AKTIFITAS PELUAHAN SEBAGIAN
}

\author{
Darwison, Aulia* \\ Jurusan Teknik Elektro, Fakultas Teknik, Universitas Andalas, Padang \\ *Corresponding author, e-mail: aulia@ft.unand.ac.id
}

\begin{abstract}
Abstrak - Korelasi antara jumlah pulsa peluahan sebagian (PD) dengan tingkat kerusakan permukaan sampel dikaji dalam makalah ini. Pengkajian dilakukan dengan menguji sampel berbeda dari komposit polietilen berkerapatan rendah (LDPE) dan karet alam (NR) di bawah pengaruh medan listrik tinggi selama 60 menit. Hasil memperlihatkan adanya korelasi yang kuat antara citra permukaan sampel setelah pengujian dengan jumlah pulsa PD yang terhitung. Jumlah pulsa PD yang tinggi berkorelasi dengan luas citra pemukaan sampel rusak yang lebih besar.
\end{abstract}

Kata Kunci : peluahan sebagian, komposit, polietilen, karet alam, citra permukaan

\begin{abstract}
The correlation between the partial discharge (PD) pulses count and the surface of the related sample was studied and reported in this paper. The assessment was done by testing different samples of the composite low density polyethylene (LDPE) and natural rubber (NR) under a high electric field for 60 minutes. The results showed a strong correlation between the images of the sample surface after testing by the number of PD pulses is counted. The high of PD pulses counted are highly correlated with the larger scale of surface area damaged.
\end{abstract}

Keywords : partial discharge, composite, polyethilene, natural rubber, surface picture

Copyright $@ 2017$ JNTE. All rights reserved

\section{PENDAhUluan}

Kerusakan permukaan isolasi listrik akibat peluahan sebagian merupakan phenomena umum apabila material tersebut berada di bawah pengaruh medan listrik tinggi. Tingkat kerusakan permukaan bahan mengindikasikan besarnya pengaruh peluahan sebagian terhadap bahan tersebut dan sebaliknya juga menggambarkan tingkat ketahanan material tersebut terhadap aktifitas peluahan sebagian. Korelasi antara tingkat kerusakan dan aktifitas peluahan sebagian yang ditandai dengan citra yang berbeda di daerah yang dipengaruhi medan lsitrik tinggi masih terus dikaji. Pada makalah ini ditampilkan hasil kajian tersebut tapi dengan menggunakan bahan isolasi baru yang terdiri dari polietilen berkerapatan rendah (LDPE) dan karet alam.

\section{TINJAUAN PUSTAKA}

Analisis PD sangat penting dilakukan untuk mendukung perkembangan teknologi isolasi listrik tegangan tinggi. Pola PD, besarnya PD dan fase tegangan yang diberikan adalah metode diagnostik yang sudah dikenal untuk menganalisis isolasi peralatan tegangan tinggi. Analisis dilakukan dengan membandingkan akumulasi basis data yang memberikan korelasi antara pola PD dan status isolasi seperti degradasi atau cacat. Studi menunjukkan bahwa sifat PD tergantung pada tegangan yang diberikan dan frekuensi tetapi tidak terpengaruh oleh tegangan offset yang diterapkan [1]. Analisis PD digunakan untuk menilai berbagai bahan isolasi seperti LDPE, XLPE, nano polimer isolasi bahan dan jenis lain dari polimer [2-10].

Cara yang paling umum menggambarkan data PD adalah dengan memakai grafik $\varphi$-q-N yang mewakili sudut pasa PD $(\varphi)$, muatan ratarata PD $(q)$ dan jumlah pulsa (N) [11]. Grafik ini dikenal dengan pola phase resolved $\mathrm{PD}$ (PRPD). Dengan menggunakan grafik tersebut, sudut pasa, jumlah pulsa dan besar muatan PD dapat dianalisis. Walaupun jumlah pulsa PD adalah salah satu parameter penting dalam PRPD, tapi analisis detail dan hubungannya dengan tingkat kerusakan permukaan bahan isolasi tidak banyak ditemukan. 
Pada setiap kejadian PD, permukaan isolasi akan mengalami kerusakan secara bertahap. Kerusakan ini akan menyebabkan citra permukaan sampel isolasi juga akan berubah dari keadaan sebelum dan sesudah pengujian PD. Diyakini bahwa jumlah pulsa PD akan mempengaruhi besar area kerusakan permukaan isolasi. Besarnya pengaruh kerusakan dapat dianalisis dengan beberapa teknik pengolah citra, salah satunya adalah teknik pengolah citra statistik.

Secara statistik, sebuah gambar histogram dapat menggambarkan distribusi intensitas dari sebuat citra digital yang berbentuk pixel untuk setiap intensitas. Sumbu horizontal (X) adalah variasi warna dan sumbu vertikal (y) jumlah pixel dari setiap warna terkait. Pada sumbu horizontal sebelah kiri menggambarkan warna yang paling hitam dan dan yang paling kanan menggambarkan warna yang paling terang.

Dalam menganalisis tingkat keruskaan permukaan perlu diperhatikan kualitas gambar untuk memberikan hasil histogram yang tepat. Kualitas gambar dapat dipertahankan dengan pendekatan beberapa teknik seperti metoda penjumlahan kesalahan (error summation) ataupun dengan metoda histogram-based image quality index [12] dan the Bayesian image estimation [13].

\section{METODOLOGI}

Bahan yang dipakai pada pengujian peluahan sebagian merupakan bahan baru yang terbuat dari bahan dasar polietilen kerepatan rendah (LDPE) dan karet alam (NR) yang dicampur pada komposisi yang berbeda. Bahan sampel ini diuji di bawah medan listrik tinggi yang disuplai dari sumber AC $6.5 \mathrm{kV}$. Selama pengujian direkam data PD melalui sistim data akuisisi otomatis dan disimpan di dalam hardisk untuk keperluan analisis selanjutnya. Sebelum dan sesudah pengujian foto permukaan sampel diambil untuk dibandingkan keadaanya dan dianalisa dengan menggunakan perangkat lunak LabVIEW produksi perusahaan National Instrument (NI).

\subsection{Sampel Isolasi}

Tabel 1 memperlihatkan komposisi sampel LDPE-NR yang akan diuji. Sampel dipersiapkan dengan mencampur LDPE-NR dengan komposisi yang berbeda. Pencampuran dilakukan dengan menggunakan penggiling kembar panas pada suhu $160^{\circ} \mathrm{C}$. LDPE dicairkan terlebih dahulu sampai merata, selanjutnya ditambahkan NR dengan jumlah yang telah ditetapkan. Langkah selanjutnya adalah mencetak sampel LPDE-NR dalam bentuk lembaran setebal $1 \mathrm{~mm}$ dengan lebar dan panjang 200x200 mm dengan menggunakan mesin tekan panas. Proses terakhir adalah proses pendinginan dengan mesin pendingin tekan.

Tabel 1. Komposisi sampel isloasi LDPE-NR

\begin{tabular}{|c|c|c|}
\hline Sampel Name & LDPE (gram) & NR (gram) \\
\hline A1 & 100 & - \\
\hline A2 & 90 & 10 \\
\hline A3 & 80 & 20 \\
\hline A4 & 70 & 30 \\
\hline
\end{tabular}

\subsection{Rangkaian Pengujian}

Gambar 1 adalah rangkaian uji PD dengan sumber tegangan bola-balik $50 \mathrm{~Hz}$ dengan tegangan puncak rms $6.5 \mathrm{kV}$ rms. Jenis sel uji yang dipakai adalah CIGRE Method II. Rangkaian pengujian ini dilengkapi dengan sistim akuisisi data menggunakan DAQ picoscope yang terhubung ke PC atau Laptop.

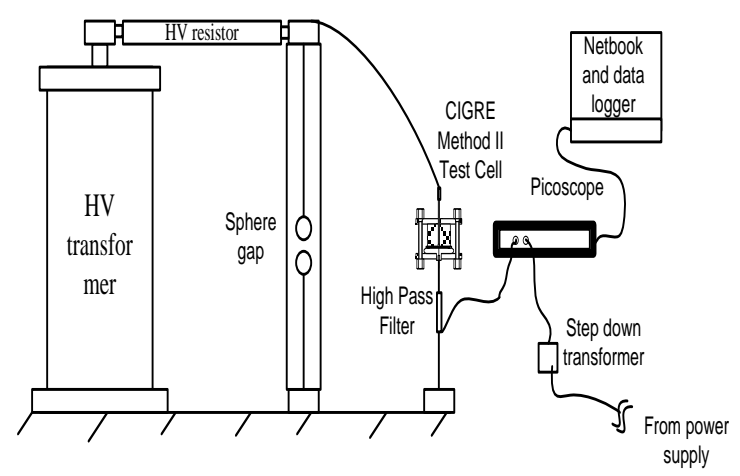

Gambar 1. Rangkaian uji peluahan sebagian

\section{HASIL DAN PEMBAHASAN}

\subsection{Analisis Jumlah Total PD}

Gambar 2 menunjukkan jumlah total pulsa PD untuk sampel LDPE-NR dengan komposisi yang berbeda (A1, A2 dan A4) dimana jumlah pulsa PD di bawah 6000, kecuali sampel A3, yang hampir berjumlah 16.000. Jumlah total pulsa PD sampel A1 sedikit lebih tinggi dari sampel A4, namun jumlah PD pulsa total untuk sampel A2 jauh lebih rendah dari pulsa sampel A1, A3 dan A4. Dengan persentase berat NR 
yang lebih tinggi (wt\%) diharapkan ketahanan PD komposit LDPE-NR juga akan meningkat.

Ditemukan bahwa jumlah pulsa PD untuk sampel A3 lebih besar sampel A2 dan A1. Hal ini terjadi karena banyak faktor, termasuk kemungkinan adanya void selama persiapan sampel yang kemudian mengarah ke resistance PD lebih rendah dari itu untuk dasar atau referensi bahan isolasi. Meskipun sampel A4 memiliki ketahanan PD lebih tinggi dari sampel A3, tapi peningkatan tersebut hanya sedikit lebih tinggi sampel A1.

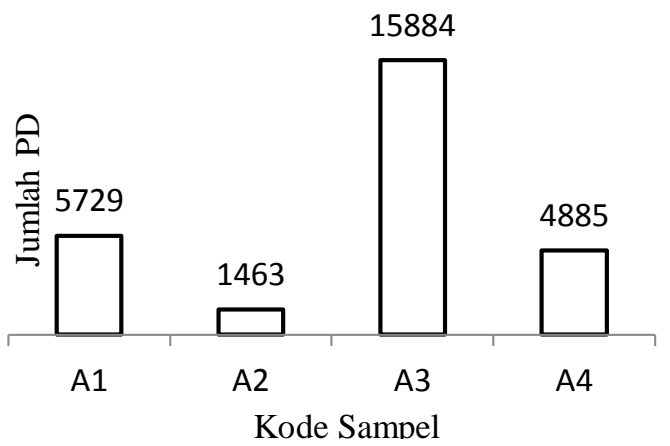

Gambar 2. Total hitungan pulsa PD dari sampel LDPE-NR yang berbeda selama pengujian medan listrik tinggi; sampel A1, A2 A3 dan A4

Analisis di atas memperlihatkan bahwa jumlah pulsa PD sampel A2 adalah yang terkecil dan sampel A3 yang terbanyak. Penambahan NR ke LDPE dengan jumlah kecil atau sam dengan $10 \mathrm{wt} \%$ memperlihatkan peningkatan ketahan komposit LDPE-NR terhadap aktifitas PD.

\subsection{Analisis Citra Permukaan komposit LDPE-NR}

Gambar 3 menunjukkan citra sampel A1 (100: 0) sebelum dan sesudah medan listrik tinggi diterapkan selama 60 menit. Perbedaan kondisi permukaan sebelum dan sesudah tes jelas diidentifikasi. Beberapa bintik hitam secara acak terletak dengan ukuran berbedal terlihat dengan jelas. Bintik-bintik gelap menandakan telah terjadinya proses karbonisasi akibat kegiatan PD. Perlu dicatat bahwa bintik-bintik gelap hanya dapat dilihat dengan menggunakan kamera pembesar.

Gambar 3 (c) dan (d) menunjukkan morfologi permukaan sampel sebelum dan setelah stres. Dengan menggunakan pendekatan analisis wavelet, kekasaran permukaan dari dua gambar bisa dibedakan dengan mudah. Ada lebih banyak tonjolan pada Gambar 3 (d), sedangkan tidak ada atau kurang tonjolan terlihat pada Gambar 3 (c). Permukaan yang menonjol menunjukkan tingkat kekasaran permukaan yang menggambarkan kerusakan permukaan karena penerapan tegangan tinggi pada sampel A1.

Gambar 3 (e) dan (f) menampilkan gambar 3D dari sampel A1 sebelum dan sesudah pengujian PD. Gambar dalam warna grayscale, mulai dari 0 sampai 255 . Nilai dari warna gelap adalah 0, sedangkan warna terang adalah 255 . Jelas, daerah cacat adalah dalam kisaran nilai yang lebih kecil atau warna gelap.
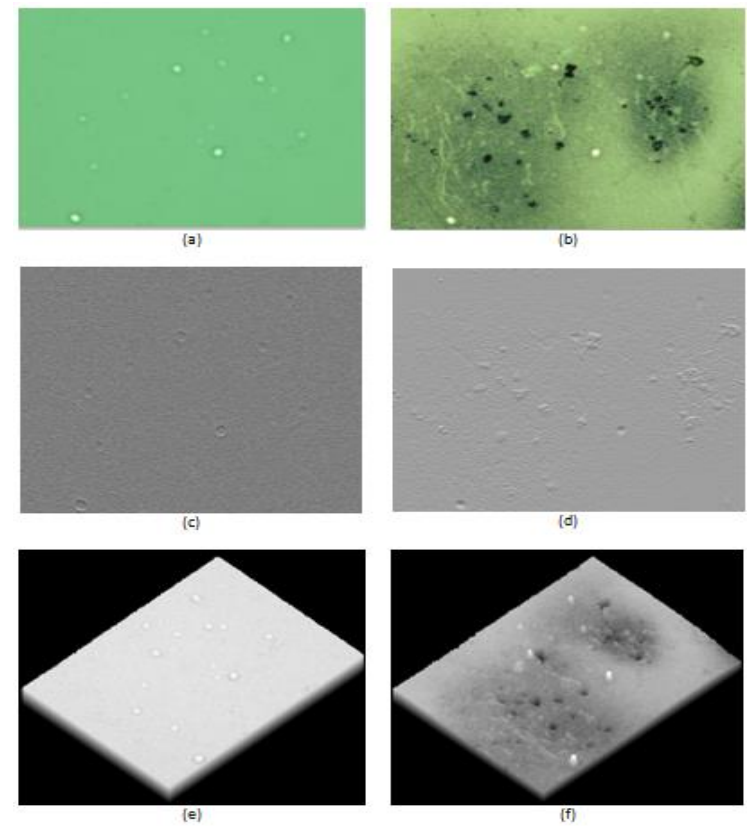

Gambar 3. Permukaan komposit LDPE-NR sampel A1 sebelum dan setelah pengujian PD selama 60 menit; (a) dan (b) adalah gambar asal, (c) dan (d) adalah tekstur gambar dua dimensi (2D), (e) dan (f) adalah tekstur gambar tiga dimensi (3D)

Sebagaiman sampel A1, Gambar 4 menunjukkan gambar untuk sampel A3. Sekali lagi, gambar sampel sebelum pengujian sangat halus dan tidak ada daerah gelap seperti yang ditunjukkan pada Gambar 4 (a), (c) dan (e). Sebaliknya, setelah stres medan tinggi, gambar memiliki area gelap cukup besar seperti yang ditunjukkan pada gambar 4 (b), (d) dan (f). 
Permukaan sampel setelah stres juga sangat kasar seperti yang ditunjukkan pada Gambar 4 (d). Gambar 3D pada Gambar 4 (f) jelas menunjukkan lokasi kerusakan di permukaan sampel.
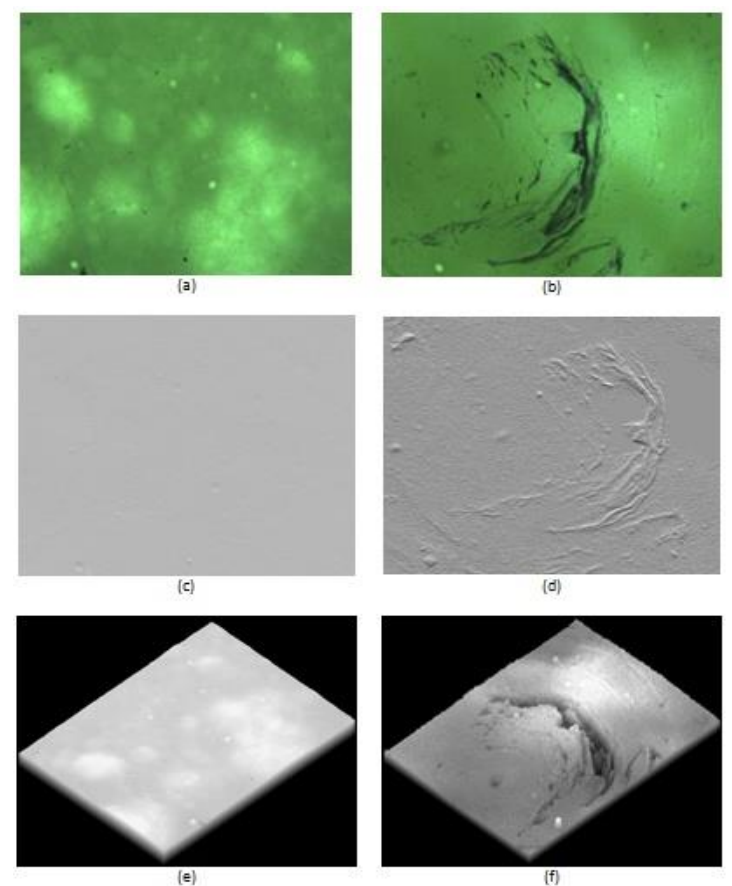

Gambar 4. Permukaan sampel komposit LDPENR (80:20) sebelum dan setelah pengujian PD selama 60 menit; (a) dan (b) adalah gambar asli, (c) dan (d) adalah tekstur gambar dua dimensi (2D), (e) dan (f) adalah tekstur gambar tiga dimensi (3D)

\section{UCAPAN TERIMA KASIH}

Ucapan terima kasih ditujukan kepada Fakutas Teknik Universitas Andalas yang telah membantu sebagian pendanaan penelitian ini dengan kontrak No. 04/UN.16.09.D/PL/2016.

\section{KESIMPULAN}

Hasil memperlihatkan adanya korelasi yang kuat antara rusaknya citra permukaan sampel setelah pengujian dengan jumlah pulsa PD yang terhitung. Jumlah pulsa PD yang tinggi berkorelasi dengan luas citra pemukaan sampel rusak yang lebih besar. Ini membuktikan bahwa bahwa aktifitas PD dapat ditandai dengan adanya kerusakan permukaan sampel.

\section{DAFTAR PUSTAKA}

[1] H. Kuwahara, K. Tsuruta, H. Munemurs, T. Ishii, and H. Shiomi, "Partial Discharge Characteristics of Silicone Liquids," Electrical Insulation, IEEE Transactions on, vol. EI-11, pp. 86-91, 1976.

[2] Y. Tani, K. Ichikawa, C. S. Kim, and T. Mizutani, "PD patterns for LDPE with needle-plane electrode," in Conference on Electrical Insulation and Dielectric Phenomena (CEIDP), Annual Report, Kitchener, ON, 2001, pp. 344-347.

[3] I.-K. Song, K.-S. Suh, and H.-R. Kwak, "Characteristics of partial discharge in various polyethylenes," in Proceedings of the Electrical/Electronics Insulation Conference, Rosemont, IL, USA, 1997, pp. 273-277.

[4] X. H. Zhang, J. G. Gao, J. M. Zhang, N. Guo, Q. Q. Ji, and J. Y. Liu, "Characteristics of electrical breakdown and partial discharge of polyethylene/montmorillonite nanocomposites," Gaodianya Jishu/High Voltage Engineering, vol. 34, pp. 21242128, 2008.

[5] R. Miller and I. A. Black, "Partial Discharge Energy Measurements on Electrical Machine Insulation When Energized at Frequencies between $0.1 \mathrm{~Hz}$ and Power Frequency," Electrical Insulation, IEEE Transactions on, vol. EI14, pp. 127-135, 1979.

[6] T. Mizutani, T. Kondo, and K. Nakao, "Change in partial discharge properties of a void in LDPE," in Conference on Electrical Insulation and Dielectric Phenomena (CEIDP), Annual Report, Austin, TX, USA, 1999, pp. 257-260.

[7] T. Mizutani and T. Kondo, "PD patterns and PD current shapes of a void in LDPE," in Proceedings of the IEEE International Conference on Properties and Applications of Dielectric Materials, Xi'an, China, 2000, pp. 276-279.

[8] P. Tiemblo, M. Hoyos, J. M. GomezElvira, J. Guzman, N. Garcia, A. Dardano, et al., "The development of electrical treeing in LDPE and its nanocomposites with spherical silica and fibrous and laminar silicates," Journal of Physics DApplied Physics, vol. 41, Jun 212008. 
[9] C. S. Kim, T. Hirase, and T. Mizutani, "PD frequency characteristics for a void bounded with LDPE," in Conference on Electrical Insulation and Dielectric Phenomena (CEIDP), Annual Report, Cancun, 2002, pp. 712-715.

[10] F. Guastavino, A. Dardano, A. Ratto, E. Torello, M. Hoyos, J. M. GÃmez-Elvira, et al., "Resistance to surface partial discharges of LDPE nanocomposites," in Annual Report - Conference on Electrical Insulation and Dielectric Phenomena, CEIDP, Vancouver, BC, 2007, pp. 244247.

[11] A. Lapp and H. G. Kranz, "The use of the CIGRE data format for PD diagnosis applications," Dielectrics and Electrical Insulation, IEEE Transactions on, vol. 7, pp. 102-112, 2000.

[12] Y. Yalman, "A Histogram based Image Quality Index," Przeglad Elektrotechniczny, vol. 88, pp. 126-129, 2012.

[13] A. H. Baydush and C. E. Floyd, Jr., "Improved image quality in digital mammography with image processing," Med Phys, vol. 27, pp. 1503-8, Jul 2000.

\section{Biodata Penulis}

Darwison, lahir tahun 1964 di Payakumbuh Sumatera Barat. dan menamatkan jenjang pendidikan S1 tahun 1992 dari ITS, Surabaya dan jenjang pendidikan S2 di UGM, Jogyakarta tahun 2001. Bekerja sebagai dosen tetap di Jurusan Teknik Elektro Universitas Andalas dan sekarang sedang menyelesaikan jenjang pendidikan S3 di Universtias yang sama. Ketertarikan penelitian adalah di bidang tegangan tinggi mekatronika, signal dan sensor.

Aulia, dilahirkan di Payakumbuh, Sumatera Barat pada tahun 1968. Menamatkan jenjang pendidikan S1 di UNSRI, Indralaya, Sumatera Selatan tahun 1996, jenjang pendidik S2 dan S3 di UTM, Johor, Malaysia pada tahun 2009 dan 2016. Sekarang bekerja sebagai dosen di Jurusan Teknik Elektro Universitas Andalas. Ketertarikan terhadap penelitian adalah di bidang teknik tegangan tinggi dan energi baru dan terbarukan. 